\title{
The woman, partner and midwife: An integration of three perspectives of labour when intrapartum transfer from a birth centre to a tertiary obstetric unit occurs
}

Lesley J. Kuliukas ${ }^{1,2}$ RM, MA. Lecturer

Yvonne C. Hauck ${ }^{1,2}$ RM, PhD. Professor of Midwifery

Lucy Lewis $^{1,2}$ RM, PhD. Research Fellow

Ravani Duggan ${ }^{1}$ RM, PhD. Senior Lecturer

1. School of Nursing, Midwifery and Paramedicine, Curtin University, GPO Box U1987, Perth: Western Australia.

2. Department of Nursing and Midwifery Education and Research, King Edward Memorial Hospital PO Box 134, Subiaco, Western Australia 6904

Corresponding author: Lesley Kuliukas 1.kuliukas@curtin.edu.au Curtin University, GPO Box U1987, Perth, Western Australia. Tel: 0420362102. 


\begin{abstract}
Background: When transfer in labour takes place from a birth centre to a tertiary maternity hospital the woman, her partner and the midwife (the triad) are involved, representing three different perspectives. The purpose of this paper is to explore the integration of these intrapartum transfer experiences for the birth triad.
\end{abstract}

Methods: Giorgi's descriptive phenomenological method of analysis was used to explore the 'lived' experiences of Western Australian women, their partners and midwives across the birth journey. Forty-five interviews were conducted.

Findings: Findings revealed that experiences of intrapartum transfer were unique to each member of the triad (woman, partner and midwife) and yet there were also shared experiences. All three had three themes in common: 'The same journey through three different lenses'; 'In my own world' and 'Talking about the birth'. The woman and partner shared two themes: 'Lost birth dream' and 'Grateful to return to a familiar environment'. The woman and midwife both had: 'Gratitude for continuity of care model' and the partner and midwife both found they were: 'Struggling to adapt to a changing care model' and their 'Inside knowledge was not appreciated'.

Conclusion: Insight into the unique integrated experiences during a birth centre intrapartum transfer can inform midwives, empowering them to better support parents through antenatal education before and by offering discussion about the birth and transfer after. Translation of findings to practice also reinforces how midwives can support their colleagues by recognising the accompanying midwife's role and knowledge of the woman. 


\section{Introduction}

\section{Summary of relevance}

\section{Problem}

Intrapartum transfer from midwife-led to obstetrician care is relatively common but there is little knowledge regarding the impact on women, their partners and midwives.

\section{What is Already Known}

Intrapartum transfer causes disappointment, trauma and stress for each individual party involved.

\section{What this Paper Adds}

There is no published literature comparing the experiences of the three involved parties. This paper makes comparisons between the three and offers insight into what each one is experiencing, how their journeys compare and how this knowledge can improve care.

The birth of a baby is a pivotal day in a woman's life with women stating they remember the highs and lows, the exhaustion, the despair and the exhilaration. ${ }^{1}$ The overall experience changes if her birth plan is not realised due to problems occurring during labour..$^{2-4}$ Women who plan to birth in a low risk centre but are required to transfer to a tertiary referral unit experience a range of emotions including concern, fear and disappointment. ${ }^{5,6}$ However, the woman's recollection and memory of this event is one perspective. Within the birthing room there are usually at least three people; the woman, her life partner and the midwife; the birth triad. Each of these participants approaches the birth journey independently and lives the experience in a different way. They are influenced by a variety of factors such as hormones, expectations, hopes, policies and legal requirements..$^{7-10}$ The three perspectives mean that the birth journey is viewed through lenses with individualised foci, however, because each 
participant is so immersed in their own journey they may have limited insight into the experiences of others.

The findings of this paper are part of a larger qualitative study in which the overall experiences of women, partners and midwives were independently examined when transfer took place in labour from a low risk birth centre to a tertiary obstetric unit. ${ }^{7,10,11 .}$ The purpose of this unique paper is to explore the integration of the lived experiences of an intrapartum transfer within the labour journey for the birth triad (the woman, her partner and the midwife).

\section{Literature review}

Childbirth choices for women in Western Australia are divided into private or public care, within a variety of options. Women can birth in a private hospital with care being provided by a private obstetrician or a public hospital under a public hospital consultant, with care provided by the medical and midwifery team. Alternatively, women can select a birth centre or home birth with care provided by a midwife, either through a government funded program or independent practice together with medical collaboration as necessary. Of the 33,393 women who gave birth in 2012 in Western Australia, 324 (1\%) were in a birth centre. ${ }^{12}$ Couples who plan for birth centre care often do so in order to have some degree of choice and control around labour and birth decisions. ${ }^{13}$ However labour does not always progress according to plan and women and partners can be confronted by the unexpected when intrapartum transfer becomes necessary. ${ }^{2-5,10,14 .}$

When transfer in labour from a low risk area, such as home or birth centre, to a referral centre occurs it has been identified that women experience a feeling of failure and disappointment. An English qualitative study ${ }^{5}$, confirmed that these overwhelming emotions were experienced by 12 women. Another mixed methods Swedish study ${ }^{14}$ concluded that women who were transferred described negative birth experiences. Feelings of negativity were also confirmed in two further English studies which discovered a perceived loss of 
choice, continuity and control, contributing to feelings of anger, resentment and not belonging. ${ }^{2,3}$ The woman's partner, the second member of the triad, who generally aims to offer support in order to help achieve the labour that was planned for, is also affected by the labour experience. ${ }^{15-17}$ Partners of women choosing to birth in a birth centre have been acknowledged as feeling more involved in the care ${ }^{18}$ however, this increased involvement may contribute to the range of emotions that have been described when the anticipated path of labour changes. ${ }^{10}$ Partners are known to feel sidelined and excluded when transfer takes place but believe that they could play an important and beneficial role because of their inside knowledge of the woman. ${ }^{10}$

In the antenatal period the midwife informs and educates the couple to enable planning for their desired birth. When intrapartum transfer occurs, the midwife, the third member of the triad, has to react in a timely fashion ${ }^{19}$ whilst reassuring the parents and facilitating the transfer which can, according to recent American and English qualitative studies, cause stress ${ }^{20}$ and fear. ${ }^{21}$ The English study which used phenomenological methodology, analysed interviews of 10 midwives who were involved in a home to hospital transfer situation and discovered five main themes; the decision to transfer; the importance of supporting the parents; the significance of collaborative working; the ongoing organisational challenges; and the need for a reliable ambulance service. ${ }^{20}$ The American qualitative study, which also focused on the home to hospital experience, found the transferring midwives described three themes; a perceived lack of holistic care by the receiving staff, the bias of physicians and in the third theme the midwives wanted physicians to have insight into the poor national obstetric outcomes rather than being focused on the small number of homebirth transfers. ${ }^{21}$ An Australian qualitative study recently demonstrated that when the midwife arrives with the transferring couple at the tertiary referral centre there are feelings of role confusion and unfamiliarity. ${ }^{7}$ Findings from these studies suggest that the midwife relies on 
confidence and expertise when making the decision to transfer and that this decision may result in fear and anxiety. The need for openness and honesty with parents and collaboration with other health care professionals was discussed, with a focus on communication, teamwork and support..$^{7,20,21}$

Although three separate pathways have been considered independently, there is currently no literature describing the integration of the interwoven journey of the three main participants when transfer in labour takes place from a birth centre to a tertiary obstetric hospital.

\section{Participants and Methods}

The study was conducted at a birth centre in Western Australia, on the grounds of a tertiary obstetric hospital, which provided woman-centred, midwifery-led care for low risk women. The outcomes in the birth centre reflected existing evidence whereby women have lower rates of intervention, operative birth and pharmacological analgesia. ${ }^{22-24}$ The purpose of this paper is to describe the integration of the 'lived' experiences of an intrapartum transfer within the labour journey for the women, their partners and accompanying midwives and Giorgi’s descriptive phenomenological philosophy was the chosen method used. ${ }^{26}$

Study inclusion criteria comprised women booked for birth centre care and their partners, who read and spoke English, who laboured in the birth centre but were transferred to the tertiary obstetric unit during the first or second stages of labour, accompanied by a known midwife. The midwife was included if she remained with the woman to provide care in the tertiary obstetric unit following transfer. Ethical approval was obtained from the University's Human Research Ethics Committee (HR91/2013) and the Hospital Human Ethics committee (2013031EW).

As the first author was a birth centre midwife, experienced in intrapartum transfer, it was decided follow Giorgi's philosophy ${ }^{26}$ and use reflexive bracketing to identify 
preconceived ideas and assumptions prior to collecting data to reduce bias. Reflexive bracketing facilitates reflection to reveal personal values and background. ${ }^{27}$ In addition, the first author was an employed peer of the midwives recruited to the study.

Recruitment occurred from mid-July to mid-October 2013 using purposive sampling, ${ }^{26}$ with participants recruited in the birth centre or hospital postnatal ward. If the woman was discharged prior to recruitment, the woman and partner was contacted by telephone within four weeks post birth. The midwife was contacted and interviewed as soon after the birth as possible and clinical records were made available to prompt reflection of the journey with that particular couple. An information letter was provided and consent forms signed prior to conducting interviews. Demographic information such as name, contact details, age, educational level, reason for transfer and type of birth was collected from the partner and woman's medical record and midwife details such as length of midwifery experience were gathered.

All interviews apart from two (partners) were face-to-face interviews in order to truly understand the narrative of their experiences. ${ }^{28}$ The interviews were conducted privately, in the participants' home or, for the midwives, in the birth centre. Triad members were interviewed individually, in order to minimise the influence of the other two members and to enable capturing of each participants' authentic journey. All interviews took place within 8 weeks of the birth, forty-one within 4 weeks, in order to aid recall but at the same time also allowing participants time to reflect on the experience.

The interviews followed a story-telling style beginning with a broad opening question asking for a description of the whole journey, followed by open ended prompts to encourage the participants to describe their feelings during each phase of the overall experience. The interviews were audio taped and transcribed verbatim. Each interview was listened to three further times and checked against the transcription to ensure accuracy. One interview lasted 
15 minutes but all others were 25 to 65 minutes. A reflexive diary was completed after each interview to describe any notable observations, including comments made after the recorder was switched off.

Analysis involved the use of NVivo 10 to manage the data and employed Giorgi's descriptive phenomenological method of analysis. ${ }^{29}$ Giorgi's method was chosen because it focuses on descriptions of experiences and suggests consideration be given to the same phenomenon as it manifests to each individual. ${ }^{30}$ Each group of transcriptions were separated into NVivo nodes which formed a recognisable aspect of the individual's experience.

Comparison was then made between the three node groups and it became obvious that there was an integration of themes of the three parties demonstrating some similarities of experiences. Some themes were shared by two of the parties and there were individual themes indicating singular experiences. The themes were then mapped out in a triad triangle (Figure 1) representing similarities and differences and linked to direct quotes in order to demonstrate the richness of stories. ${ }^{29}$

To reduce bias and enhance confirmability, ${ }^{28}$ comparisons of the three node groups was also independently performed by the three other members of the research team. Similarities were found by all team members although negotiation and refinement occurred to confirm findings accurately reflected the integration of experiences. The team were female, clinical or academic midwives.

\section{Findings}

Data collection was in the form of interviews with a total of 45 individual interviews took place, making a total of 15 triads (women, partners and midwives) which, according to Giorgi forms sufficiency of data ${ }^{31}$. It was considered that sufficiency was reached when the narratives appeared to have revealed full and comprehensive interpretations of events with as much variation as possible and also beginnings of repetition were being heard. Eleven 
primiparous and four multiparous women participated. Maternal ages ranged from 22 to 38 years (mean 31 years), and partners were 24 to 39 years (mean 33), with 13 couples having a tertiary level education. Eleven midwives were interviewed for the 15 birth experiences: four were interviewed twice for their experience with two couples. Midwifery experience ranged from 1 to 30 years (mean 18 years) with an average of 6.7 years ( 0.5 to 20 years) in a birth centre. The coding system for quotes from triads 1-15 (T1-15) are separated for women (W115), partners (P1-15) and midwives (M1-15).

\section{Integration of the journeys of the woman, partner and midwife}

Asking about the whole labour and birth journey allowed each participant to describe their own individual pathway giving rise to different views or perceptions of the same experience. Analysis took place as described above by comparing the 3 node groups from 3 sets of qualitative data against each other, revealing integration of similar experiences. Figure 1 illustrates how the experiences of triad members are pulled together whilst they simultaneously have a singular unique view. The three subthemes within the integration of the triad experiences were: 'In my own world', 'Talking about the birth' and 'The same journey through three different lenses'.

\section{In my own world}

'In my own world', emerged from each triad member being immersed in their own emotions. The woman's body, full of endorphins and oxytocin, took over the business of birthing whilst she was inwardly focused. The partner's perspective was influenced by his high levels of anxiety and stress causing the 'fright/fight/flight' mode which resulted in a level of high alertness and sensitivity to what was happening. The midwife's perspective resulted from a sense of responsibility to ensure the parents were provided with what they desired while simultaneously feeling incumbent to ensure a healthy outcome. 
The reality of each experiencing an inner world was demonstrated by Triad 10 as each gave a typical report of these three perspectives. The woman described how she had little recollection of certain events because of being 'in the labour zone': I can't remember a lot you know... I had no concept of time or of anything that was going on around me... I was just on another planet really. It did feel like I wasn't really there (W10). In contrast her partner remembered with great clarity his emotions watching his wife during her prolonged labour: $I$ had a feeling all the way along ... it's not going to plan. I was just really concerned about B being so exhausted .... It just felt I mean the whole thing was agony really (P10). While these thoughts were going on for the woman and her partner, the midwife was having her own internal conversation, completely immersed, wondering why there was no progress in the second stage. She carried out a vaginal examination and said to herself: There was a heap of caput, heap of moulding, and I thought, blow, anterior fontanelle sitting at sort of 2:30 and it's like, hang on, where's my posterior fontanelle gone? My lovely little tiny triangular posterior fontanelle where are you (M10)?

\section{Talking about the birth}

The second overlapping subtheme between all three parties was an appreciation that talking about the birth afterwards was worthwhile. Women felt that because they were often 'in the zone' for their labour and birth they needed the space afterwards to clarify what had actually happened, as W8 commented: I mean no one came and told me what happened with the operation (manual removal of placenta) afterwards so it would have been nice ... for them to come and say why that happened. It would have been good to get some clarity (W8). This was reiterated by W11: It is good to talk about the experience, it helps clear things in your head (W11). Partners felt the need to de-stress by talking through what was clearly, for some, a harrowing day, as P10 stated: I definitely found it a bit traumatic ... I was so surprised with how intense the whole saga is... It's good to talk about it. 
Midwives talked about informal debrief that takes place on a daily basis, as described by M12: You do it informally as in when the next midwife comes on. However, other midwives, like M13 felt it should be a learning exercise, for midwives to be able to discuss which and when actions were taken: It's useful to know what you could have done differently or ask opinions of other people. After this case I wasn't sure whether I did do the right thing or not (M13). Helping to clarify the labour pathway by talking afterwards about it was reiterated by M9: It's useful, until we verbalise it sometimes it doesn't make sense.

\section{The same journey through three different lenses}

For each triad member, intrapartum transfer within the labour experience was an eventful and emotional journey, with each seeing it from their unique perspective. The women's perception was influenced by feeling exhausted and in pain whereas the partners' view came out of a sense of protectiveness, being out of their comfort zone but sometimes unable to be realistic in their expectations. The midwives' view was influenced by their satisfaction in providing care based on experience and intuition but involving periods of stress when considering whether they were making the right decision at the right time. For example, contrasting emotions and perceptions were felt by each member of Triad 2, each focused in on their own inner turmoil. The midwife felt stressed at the responsibility of everything that needed to be organised for the transfer:

Ifeel like a pressure cooker. I feel like I'm going to explode with all the conflicting worries. Worried about making the right decision, worried about getting over there without too much delay, worried about not being efficient enough when you get over there (M2).

The partner's inner emotion was frustration at not being given more time to try to allow for further progress: I was reluctant (to transfer) really, maybe we should think about another strategy, I was thinking we should keep going (P2). In contrast the woman had 
reached her limit and felt relieved at the thought of transfer: I was quite open to some kind of assistance at that point. I was really tired and didn't know what was going on and I was like, if I'm pushing but nothing is happening, what does that mean (W2)?

\section{Integrated themes between two parties}

As well as the integrated themes between all members of the triad there were overarching themes made up of shared experiences between the other member pairs: the woman and partner, the woman and midwife and the partner and midwife.

\section{Integration of woman and midwife}

The emerging subtheme from both the women and midwives' perspective was an appreciation of the continuity of care model.

\section{Gratitude for continuity of care model}

Midwives appreciated knowing the women and having the opportunity to see them through the birth journey. Equally women were grateful to be cared for by someone who followed the philosophy of woman-centred care, as W1 stated: I hoped that if it happened the midwife would be able to come with us because we knew she would be on our side and speak up for us, I felt all the birth centre midwives would know what we wanted. The midwife caring for W1 clearly felt the same way as she independently commented: I'd met her before a couple of times in the clinic... I know it will make a difference for them. I think women think it's important to know the person that's going to be looking after them (M1). Even in situations where the same midwife was unable to stay for the birth, midwives were able to reassure women that another birth centre midwife, with the same philosophy of care would be able to take over, for example M8: I said to her look, my shift ends at seven so ...the lovely C (midwife) will be up, and she'll support all of the choices that you've put in place (M8). The appreciation of having care followed through by someone with the same philosophy was commented on by W7 who was cared for by a team member she hadn't met before: I met all 
of the midwives in my team apart from M (midwife), I didn't mind though because I knew she would have the same philosophy around birth centre care, natural birth and all that (W7).

\section{Integration of partner and midwife}

The subthemes shared by the partner and midwife were 'Struggling to adapt to a changing model of care' and feelings of 'Inside knowledge not appreciated'.

\section{Struggling to adapt to a changing care model}

The two 'onlooking' triad members, the partner and midwife, shared how they found it difficult to adapt from one model of care and environment to another. The feeling of having to conform in the tertiary obstetric unit was noticed by M12: Can we... take off the CTG because she's back to normal... but we're up here now, so that's a bit tricky. Conforming with tertiary obstetric unit practice also meant loss of choice as noted by P3 who became disgruntled as preferences were taken away. Finally when the baby was born he was denied cutting the cord: I would like to have cut the cord but that offer was never extended to me either so ... I was angry at the junior doctor (P3).

\section{Inside knowledge not appreciated}

The second subtheme shared between midwives and partners was: Inside knowledge not appreciated. Some partners had a sense of being able to read their women better than anyone else and this extended to knowing when the woman had reached her limit of endurance, as P3 pointed out: I noticed a real struggle for her... her eyes were kind of wandering and she looked just like she was on drugs...you're struggling, we're going to bring you upstairs ... in the end it was me that made the decision. The midwife's perspective of 'inside knowledge' was about the woman's history and events leading up to the transfer; vital knowledge that some midwives did not think was taken advantage of, for example, M15: They don't seem to listen to me... no questions asked of me. Similarly M9 felt that the transferring midwife's role should be clarified as the advisor, the one with the history and knowledge: An 
adviser, being seen as someone who has a lot to offer in terms of advice and background to the case.

\section{Integration of woman and partner}

The subthemes shared by women and their partners were that they were 'Grateful to return to the familiar environment' of the birth centre after the birth and secondly the importance of reflecting on their 'Lost birth dream'.

\section{Grateful to return to the familiar environment}

After the birth most couples were able to return to the birth centre which enabled them to close the loop. Returning felt like going home to familiar territory where they were at ease; an aspect of care that was really appreciated, as P1 voiced: We were able to go back to the birth centre and that was fantastic because I got to stay, also appreciated by P7: Less intrusions as far as doctors coming in and bright lights and things like that. The fact that family members were able to stay at the birth centre was appreciated by P13 who had no family in Australia so was delighted his toddler was able to stay: The best thing ... all family can stay overnight.. This was corroborated by his wife (W13): Birthing centre is good in that way that we can stay together after the birth. The opportunity for family members to stay was also valued by W14: The bonding with a new family; that meant so much. The psychological impact of returning to a familiar environment was expressed by P3: I think the most beautiful thing about the whole experience was that as soon as $K$ got back to the room she was okay, and supported by his wife (W3): As soon as I got to the birthing centre I just felt so much better, like arriving at home, a feeling of peace, comfort, familiarity.

\section{Lost birth dream}

The birth dream of couples anticipating a birth centre birth is often one with soft lights, familiar environment and known carers. ${ }^{32,33}$ The investment into preparation for this birth meant that for many transfer was an eventuality they had not prepared for which caused 
anguish, as P12 described: I was, yeah concerned because now we're heading to the hospital which was not like the birth centre, all natural, suddenly you're getting wheeled into the hospital where it all very clinical. The decision to choose a birth centre birth was based on using water for labour and birth so when this was denied, there was disappointment : Because I'd always wanted a waterbirth, that's why I went with the birthing centre and so... was disappointed about missing out on the birth I wanted (W15). This was also independently confirmed by her partner (P15) who remembered the moment the decision was made: It was disappointing because I knew at that point that was the waterbirth out the window.

\section{Discussion}

Our findings suggest that when intrapartum transfer occurred from a birth centre to a tertiary obstetric unit there were commonalities and differences in the labour and birth journey for the woman, her partner and accompanying midwife. The normal path of labour was disturbed which impacted them all, but in different ways. It has been suggested that disturbances during labour and birth can change birth moods and cause tension ${ }^{34}$ and in this WA study the disturbance was in the form of moving from a familiar to an unfamiliar medicalised environment which a concealed constitutive mood at birth can be seen. The view of events was seen through three distinct lenses, with the women's view being through the haze of labour hormones, immersed in a timeless zone, focused on reaching the ultimate end to her journey. In contrast the partners were in a state of raised anxiety, on high alert and felt sometimes excluded and sidelined. The midwives were juggling responsibility, timely decision making and the safety of the woman and baby with trying to ensure communication channels stayed open and choices were offered. Although this was one birth journey it was perceived in three ways demonstrating how different perspectives impact every experience. Each angle and perception was distinct from the other two but there were also areas where similar experiences allowed insight across the three parties. Similar to the work of Crowther 
et al., ${ }^{34}$ which explored the mood of joy at birth through stories from women, partners, midwives and obstetricians, perceptions from all parties offered a deeper understanding of the phenomenon and contributed to greater insight on how the joy of birth may be protected.

'The subtheme, In my own world, emphasised that all members of the birth triad have their own feelings, priorities and perceptions. Each member was consumed in their own world and what that meant to them at each particular point, 'The same journey through three different lenses' demonstrated how interpretation of events is dependent on the individual viewer's perspective.

Maternity care providers need to be aware of the perspectives of the woman and the partner, in order to customise care that reflects and addresses their needs across the labour journey. Intrapartum transfer is known to be a stressful and busy time for midwives ${ }^{7}$ and necessitate a "mind shift"19 but there is a need to streamline the procedures in order to be able to focus on the couple's needs. The partner is very anxious at this time ${ }^{10}$ and the woman usually exhausted and in pain ${ }^{35,36}$ therefore it is essential that both are given explanations and reassurance to acknowledge the emotions of the transfer process. ${ }^{10}$

The other subtheme which shared commonalities between all members of the triad demonstrated that an opportunity to debrief or talk after the birth about what happened was considered important. Because of increasing time demands, finding quality time to talk about what unfolded is not always factored into postnatal care ${ }^{37}$ but it is universally accepted that women benefit from the opportunity to talk through the events of their labour. ${ }^{38} 37$ Increasing evidence also suggests that partners value the opportunity to revisit events as well, to clarify them in their mind and be given the opportunity to discuss the journey. ${ }^{10}$ This Western Australian study also revealed that midwives welcome the chance to be able to learn from their labour management and enhance reflective practice by talking through experiences with colleagues shortly after the birth. ${ }^{7}$ 
The subtheme for women and midwives, 'Gratitude for continuity of care model' is confirmation of the published literature that continuity is beneficial for both the woman and midwife. ${ }^{39}$ Our findings confirm how a group of midwives with the same philosophy were able to provide a high quality service from the woman's perspective, even if she had not met the particular midwife before her labour started.

The partner and midwife gave different perspectives within two subthemes, 'Struggling to adapt to a changing care model' and 'Inside knowledge not taken advantage of'. The first subtheme reveals an anxiety associated with moving to a model of care at odds with the philosophy of the birth centre. The main issue was reduced choices for the couples which was also concerning for the midwives. There was despondency from some partners when they felt more excluded from the labour they had planned and prepared for. Although in emergency situations options such as cutting the cord may not be accommodated, in many cases in this study reasons for reducing choices were not always explained, leaving the partner feeling excluded with diminished control and participation. It is recognised that women report higher levels of satisfaction when they are involved in their care, ${ }^{40}$ presumably the same may be true for partners. Having choices removed and not being as involved as intended had a negative impact on these Western Australian partners.

Both the partner and midwife felt the information, history and knowledge they had of the woman was not acknowledged during the transfer experience. The partner felt his ability to interpret the behaviours of the woman he knew best could be useful in helping maternity carers gain better understanding of her needs at different points in labour, which could be used to make timely decisions. It is recommended that receiving staff respect and acknowledge the partner's role in the birth journey. In an American study it was demonstrated that transferring midwives are frequently dismissed by receiving staff rather than being asked questions about the woman's history. ${ }^{21}$ Our Western Australian findings confirmed that the 
transferring midwife often feels she is a valuable resource in terms of knowledge but this is not appreciated by the tertiary obstetric unit staff. A clinical handover tool, ISOBAR ${ }^{41}$ gives guidance to ensure that pertinent information is relayed as comprehensively, yet concisely as possible by following the acronym: Identify, Situation, Observations, Background, Agreed Plan, Read back. The Background section could be expanded upon to capture this information and provide a full picture of the transferring woman.

The shared experiences of the woman and partner included 'Grateful to return to familiar environment' and 'Lost birth dream'. The lost birth dream was expressed by disappointment at not achieving the non-intervention labour and birth in a birth centre setting that they had hoped for. A continuity of care model could help in this situation, as demonstrated previously, particularly in adverse situations, such as intrapartum transfer. ${ }^{42,43}$ The second subtheme, 'Grateful to return to familiar environment' reflected the benefit to couples of being able to return to the birth centre again after the birth. Being able to return to this comfortable familiar place could be another way to mitigate the negative impact of the lost birth dream. The offer of going straight home from the tertiary obstetric unit labour ward (if all is within normal limits) is another way to achieve the positive benefit of new parents' appreciation of being able to spend time as a new family ${ }^{44}$ with the opportunity to debrief being offered by the midwife during a postpartum home visit.

The perceptions of this sample of birth centre consumers and midwives may not reflect those in different cultural and geographic locations and must be considered as a limitation. However rich descriptions of participants, methods and findings have been provided to assist the reader to determine the transferability of findings to other contexts.

\section{Conclusion}

When intrapartum transfer takes place from a low risk birth centre to a tertiary obstetric unit the experience is shared by three parties who see the journey through their own 
lenses. Each is absorbed in their own world, with the woman 'in the zone', the partner in a heightened sense of awareness and the midwife responsible for ensuring a safe outcome. Shared perceptions must be appreciated including the opportunity to talk about the birth and have their experience acknowledged whilst facilitating personal reflection. The midwife and woman confirmed the value of a continuity of care model and the midwife and partner acknowledged that their in-depth knowledge of the woman could be better utilised. Adjusting and accepting the medical model of care after transfer was a challenge and new parents' shared loss for their desired birth must be recognised. Having insight of individual and common experiences across the birth triad will provide maternity carers with knowledge to tailor their care to all participants and facilitate a positive labour and birth experience when transfer in labour is necessary. 


\section{References}

1. Callister LC. Making Meaning: Women's Birth Narratives. Journal of Obstetric, Gynecologic, \& Neonatal Nursing 2004; 33(4): 508-18.

2. Walker J. Women's experiences of transfer from a midwife-led to a consultant-led maternity unit in the UK during late pregnancy and labor. Journal of midwifery \& women's health 2000; 45(2): 161-8.

3. Rowe RE, Kurinczuk JJ, Locock L, Fitzpatrick R. Women's experience of transfer from midwifery unit to hospital obstetric unit during labour: a qualitative interview study. BMC Pregnancy Childbirth 2012; 12(1): 129.

4. Kuliukas L, Ritchie S, Lewis L, Hauck Y. Women's perceptions of midwife-led care at a family birth centre in Perth. Midwifery News 2013; Spring: 24-6.

5. Creasy JM. Women's experience of transfer from community-based to consultant-based maternity care. Midwifery 1997; 13(1): 32-9.

6. Lindgren $\mathrm{H}$, Rådestad I, Hildingsson I. Transfer in planned home births in Sweden - effects on the experience of birth: A nationwide population-based study. Sexual \& Reproductive Healthcare $2011 ; 2(3): 101-5$.

7. Kuliukas LJ, Lewis L, Hauck YL, Duggan R. Midwives' experiences of transfer in labour from a Western Australian birth centre to a tertiary maternity hospital. Women and Birth 2016; 29: 18-33.

8. Johansson M, Rubertsson C, Rådestad I, Hildingsson I. Childbirth - An emotionally demanding experience for fathers. Sexual \& Reproductive Healthcare 2012; 3(1): 11-20.

9. Steen M, Downe S, Bamford N, Edozien L. Not-patient and not-visitor: A metasynthesis of fathers' encounters with pregnancy, birth and maternity care. Midwifery 2011: 422-31.

10. Kuliukas L, Hauck Y, Duggan R, Lewis L. The phenomenon of intrapartum transfer from a western Australian birth centre to a tertiary maternity hospital: The overall experiences of partners. Midwifery 2015; 31(5): e87-e93.

11. Kuliukas L, Duggan R, Lewis L, Hauck Y. Women's experience of intrapartum transfer from a Western Australian birth centre co-located to a tertiary maternity hospital. BMC Pregnancy and Childbirth 2016; 16(1): 1-10.

12. Hutchinson M. Western Australia's Mothers and Babies, 2012: 30th Annual Report of the Western Australian Midwives' Notification System. In: Health Do, editor. Western Australia; 2015.

13. Cunningham JD. Experiences of Australian mothers who gave birth either at home, at a birth centre, or in hospital labour wards. Social science \& medicine (1982) 1993; 36(4): 475-83.

14. Lindgren $\mathrm{H}$, Hildingsson I, Christensson $\mathrm{K}$, Radestad I. Transfers in planned home births related to midwife availability and continuity: a nationwide population-based study. Birth 2008; 35(1): 9-15.

15. Dahlen HG, Barclay LM, Homer CSE. The novice birthing: theorising first-time mothers' experiences of birth at home and in hospital in Australia. Midwifery 2010; 26(1): 53-63.

16. Somers-Smith MJ. A place for the partner? Expectations and experiences of support during childbirth. Midwifery 1999; 15(2): 101-8.

17. Nichols MR. Paternal perspectives of the childbirth experience. Maternal-child nursing journal 1993; 21(3): 99-108.

18. Waldenstrom U. Effects of birth centre care on fathers' satisfaction with care, experience of the birth. Journal of Reproductive \& Infant Psychology 1999; 17(4): 357-68.

19. Patterson J, Skinner J, Foureur M. Midwives' decision making about transfers for 'slow' labour in rural New Zealand. Midwifery 2015; 31(6): 606-12.

20. Wilyman-Bugter M, Lackey T. Midwives' experiences of home birth transfer. Evidence Based Midwifery 2013; 11(1): 28-34.

21. Cheyney M, Everson C, Burcher P. Homebirth Transfers in the United States. Qualitative Health Research 2014; 24(4): 443-56. 
22. Brocklehurst P. Perinatal and maternal outcomes by planned place of birth for healthy women with low risk pregnancies: the Birthplace in England national prospective cohort study. $B M J$ British medical journal 2011; 343(nov23 4): d7400.

23. Hatem M, Sandall J, Devane D, Soltani H, Gates S. Midwife-led versus other models of care for childbearing women. Cochrane database of systematic reviews 2008; (4): CD004667.

24. Rooks JP, Weatherby NL, Ernst EK, Stapleton S, Rosen D, Rosenfield A. Outcomes of care in birth centers. The National Birth Center Study. The New England journal of medicine 1989; 321(26): 1804-11.

25. Rooks JP, Weatherby NL, Ernst EK. The National Birth Center Study. Part II--Intrapartum and immediate postpartum and neonatal care. J Nurse Midwifery 1992; 37(5): 301-30.

26. Giorgi. The Theory, Practice, and Evaluation of the Phenomenological Method as a Qualitative Research Procedure. Journal of Phenomenological Psychology 1997; 28(2): 235.

27. Ahern KJ. Ten Tips for Reflexive Bracketing. Qualitative Health Research 1999; 9(3): 407-11.

28. Polit $D$, Beck $C$. Essentials of nursing research: appraising evidence for nursing practice. 7 ed. Sydney: Lippincott Williams \& Wilkins.; 2010.

29. Giorgi. An application of phenomenological method in psychology. In: Giorgi A, ed. Duqesne studies in phenomenological psychology Vol II. Pittsburgh: Duquesne University Press; 1975.

30. Giorgi. Psychology as a Human Science: A phenomenologically based approach. New York: Harper and Row; 1970.

31. Giorgi A. Concerning a Serious Misunderstanding of the Essence of the Phenomenological Method in Psychology. Journal of Phenomenological Psychology 2008; 39(1): 33-58.

32. Stark MA, Remynse M, Zwelling E. Importance of the Birth Environment to Support Physiologic Birth. Journal of Obstetric, Gynecologic \& Neonatal Nursing 2016; 45(2): 285-94.

33. Symon A. Care and environment in midwife-led and obstetric-led units: A comparison of mothers' and birth partners' perceptions. Midwifery 2011; 27(6): 880-6.

34. Crowther S, Smythe L, Spence D. Mood and birth experience. Women and Birth 2014; 27(1): 21-5.

35. Baker A, Ferguson SA, Roach GD, Dawson D. Perceptions of labour pain by mothers and their attending midwives. Journal of Advanced Nursing 2001; 35(2): 171-9.

36. Niven C, Gijsbers K. A study of labour pain using the MCGILL pain questionnaire. Social Science \& Medicine 1984; 19(12): 1347-51.

37. Fullerton $\mathrm{G}$, Humphrey $\mathrm{T}$, Forrest J. One year of the postnatal debrief clinic in Aberdeen Maternity Hospital. BJOG 2015; 122: 175-.

38. Gamble J, Creedy D, Moyle W. Counselling processes to address psychological distress following childbirth: perceptions of midwives. Australian Midwifery 2004; 17(3): 16-9.

39. Page L. Research on midwifery continuity of care shows many advantages. British Journal of Midwifery 2013; 21(10): 690-.

40. McKinnon L, Prosser S, Miller Y. What women want: qualitative analysis of consumer evaluations of maternity care in Queensland, Australia. BMC Pregnancy and Childbirth 2014; 14.

41. Porteous JM, Stewart-Wynne EG, Connolly M, Crommelin PF. iSoBAR--a concept and handover checklist: the National Clinical Handover Initiative. The Medical journal of Australia 2009; 190(11): S152-6.

42. de Jonge A, Stuijt R, Eijke I, Westerman MJ. Continuity of care: what matters to women when they are referred from primary to secondary care during labour? a qualitative interview study in the Netherlands. BMC pregnancy and childbirth 2014; 14(1): 103.

43. Grigg CP, Tracy SK, Schmied V, Monk A, Tracy MB. Women's experiences of transfer from primary maternity unit to tertiary hospital in New Zealand: part of the prospective cohort Evaluating Maternity Units study. BMC pregnancy and childbirth 2015; 15(2).

44. Nilsson I, Danbjørg DB, Aagaard H, Strandberg-Larsen K, Clemensen J, Kronborg H. Parental experiences of early postnatal discharge: A meta-synthesis. Midwifery 2015; 31(10): 926-34. 


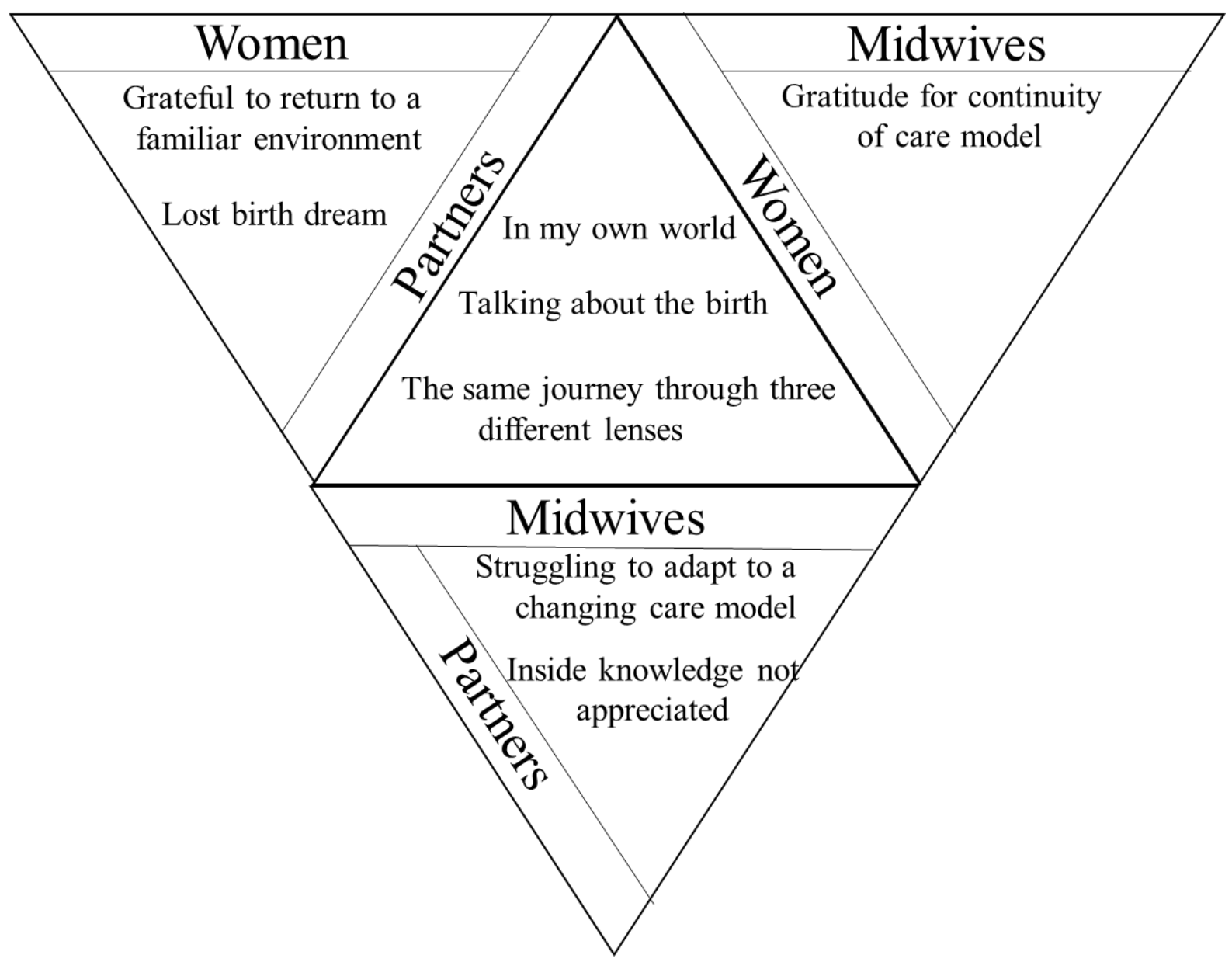

Figure 1. The triad of integrated experiences with subthemes shared by all participants with corners of the triangle representing experiences shared by two parties 